\title{
The relationship between emotional intelligence and happiness in medical students
}

\author{
Sulmaz Ghahramani ${ }^{1}$, AliReza Torabi Jahromi', Danial Khoshsoroor ${ }^{2}$, Reza Seifooripour ${ }^{2}$ and Minoo Sepehrpoor ${ }^{2}$ \\ ${ }^{1}$ Health Policy Research Center, Institute of Health and ${ }^{2}$ Students Research Committee, Shiraz University of \\ Medical Sciences, Shiraz, Iran
}

Purpose: Emotional intelligence is a factor affecting the health of individuals, and happiness is another factor affecting it. Medical students' health can greatly affect a community's health due to the important role of medical students in maintaining and improving it. Accordingly, we aimed to study the relationship between emotional intelligence and happiness among the students of the Shiraz Medical School.

Methods: This study is an analytical, cross-sectional study. The target population of this study was the medical students who began studying in the medical school and the international branch of Shiraz University of Medical Sciences from September 2014 to September 2017. The sample size was 300 students who were selected by a systematic sampling method. The instruments for collecting information in this study were Oxford Happiness Inventory and Siberia Schering's Emotional Intelligence Questionnaire. The significance level of the tests was set at 0.05 .

Results: The mean age of 292 responded participants were 20.73 with standard deviation of \pm 1.81 emotional intelligence $(p<0.001)$, level of stress $(p<0.001)$, and grade $(p=0.03)$ and type of personality $(p<0.001)$ can explain the changes in the happiness level and they were significant effective factors in the regression modeling.

Conclusion: Emotional intelligence was a predictive factor for happiness in medical students. Students with higher emotional intelligence felt healthier. And happiness in extroverted students was higher than introverted ones. It is suggested that the results of this study should be confirmed with prospective studies.

Key Words: Emotional intelligence, Happiness, Iran

\section{Introduction}

Positive psychology is a new branch of psychology the goal of which is to examine psychological capacities and powers instead of psychopathology. The fundamental belief in positive psychology is that positive, measurable features can be protective against risky adverse events. Psychologists interested in this field have focused their attention on the potential sources of positive emotions such as happiness [1].

It is suggested that happiness can be accompanied by consequences such as success in marriage, relationship, and career; and more income and health and longevity. There are, of course, some views which indicate that more successful people feel happier in their lives as a result of their success. However, in a review study conducted in 2005, the presented mental model showed
Received: November 24, 2018 • Revised: January 30, 2019 • Accepted: February 11, 2019 Corresponding Author: Sulmaz Ghahramani (https://orcid.org/0000-0002-4161-5146) Health Policy Research Center, Institute of Health, Shiraz University of Medical Sciences, Shiraz, Iran

Tel: +98.7132309615 Fax: +98.7132309615 email: Suli.ghahraman@gmail.com
Korean J Med Educ 2019 Mar; 31(1): 29-38.

https://doi.org/10.3946/kjme.2019.116

eISSN: 2005-7288

(C) The Korean Society of Medical Education. All rights reserved. This is an open-access article distributed under the terms of the Creative Commons Attribution Non-Commercial License (http:// creativecommons.org/licenses/by-nc/3.0/), which permits unrestricted non-commercial use, distribution, and reproduction in any medium, provided the original work is properly cited. 
that happiness was indeed the cause of success, not its effect [2].

Happiness has been attributed to various factors, one of which is individual personality differences. The results of studies suggest that the underlying personality structure determines people's tendency for happiness. It seems that in extrovert people, happiness is achieved through self-expression and social behavior [3].

In studies in which happiness are evaluated subjectively by asking individuals through self-report questionnaire, for expressing happiness, a person presents a cognitive and affective assessment of their entire being. In these studies, in empirical research, three components have been identified: positive affection, negative affection, and life satisfaction [4]. Therefore, a person's expressed happiness consists of cognitive and emotional dimensions. The emotional dimension of happiness can be affected by various factors. One of these factors can be emotional intelligence. Emotional intelligence is defined as a talent for understanding, feeling, and using these feelings as a basis to influence human communications. In fact, it is one's ability to recognize emotions to motivate himself/herself and to manage the emotions in communicating with people. In other words, it is one's ability to monitor the emotions of themselves and other people in order to use this information to differentiate between people and guide their thoughts and actions [5]. In general, there is a significant relationship between emotional intelligence and psychological, psychosomatic, and physical health. However, more studies are required to clarify the direct and indirect relationships between emotional intelligence and health [6]. Higher emotional intelligence as a feature can cause an individual to be able to deal with acute daily stresses and perceived chronic stress and to be even happier [7].

It is important to note that emotional intelligence and intelligence quotient are not against each other, but are different. High-intelligence individuals may have high or low emotional intelligence and vice versa [7].

The study of emotional intelligence has been the subject of many studies in different target groups including students. Increasing usage of therapeutic facilities, moving toward patient-centered care and increasing the importance of clinical competencies require a wider range of interpersonal and intrapersonal skills in the medical professions. It is even recommended that emotional intelligence is studied as a useful potential structure in assessing the desirable cognitive and non-cognitive abilities of people working in healthcare [8].

A study on the emotional intelligence of the first-year medical students showed that the emotional intelligence of these students decreased over time and it had some fluctuations. However, the clinical impact of such changes was not studied [9]. Although most medical students begin their professional education with idealism, enthusiasm, and attention to humanity, they realize during the course that they are drawn away from their path. For many, challenges including balancing their happiness, social responsibility and professional (or clinical) training can be very frustrating. The medical students' health can greatly affect the health of society due to their important role in preserving and promoting it. We aimed to study the relationship between emotional intelligence and happiness among the students of Shiraz Medical School. Shiraz University of Medical Sciences is a high rank training center in the south of Iran, with more than seventy years of medical education experience. The result of this study can be a way to help students with physical and mental health problems.

Considering the existence of an entrance test in Iran, entering the medical field needs a higher academic level than other disciplines. As a result, the intelligence rate 
of medical students is higher than that of ordinary people.

On the other hand, emotional intelligence is another factor which affects people's health [10]. As Post [11] stated in his article that happiness is another effective factor in the health of the individuals.

\section{Methods}

This research was a descriptive and cross-sectional study. The target population of this study was the students who entered Shiraz Medical School and its international branch from September 2014 to September 2017.

The sample size was calculated 285 students regarding type I error equal to $5 \%$, confidence interval equal to 95\%, and response distribution equal to 50\%. Three hundred students (150 men and 150 women; 225 students studying in Shiraz Medical School and 75 students studying in its international branch) were selected as study's sample by systematic sampling [12]. The data gathering tools were Oxford Happiness and Shering's Emotional Intelligence Questionnaires. As to grading of Happiness Questionnaire which has 29 four-choice questions, the first choice has 0 point, choice 2 has 1 point, choice 3 has 2 points, and choice 4 has 3 points. Finally, every individual has a grade from 0 to 87 and the higher grade shows more happiness. Reliability and validity of this test was evaluated and Cronbach's $\alpha$ was calculated 0.901 [13]. Shering's Emotional Intelligence Questionnaire consists of 33 five-choice questions. Grading is done by 5-point scale from 1 to 5 . The sum of the grades that every individual gains makes up for his or her total grade. Shering's Emotional Intelligence Questionnaire assesses five scales of emotional intelligence consisting of self-awareness, self-control, self-arousal, sympathy, and social skills. Reliability and validity of this questionnaire have been assessed and chronbach's $\alpha$ was calculated 0.85 [14].

Researchers attended the classes. According to the random codes which were chosen before, the questionnaires were filled out as self-report and in varying times by test subjects and their student number was used as their code. Descriptive statistics were used to describe the data and analytic statistics, such as chi-square and t-test were applied to analyze the data. Moreover, for ethical consideration, it is noted in the beginning of the questionnaire that the test subjects have contributed in this study freely and voluntarily and filling out this questionnaire means that they have free and informed consent.

\section{Results}

\section{Descriptive statistics}

Initially, the demographic data and main variables of the study including emotional intelligence and its domains (independent variables), and happiness and its domains (dependent variables) were described (Tables 1 , 2). In the following part, the main variables of the study are described by gender. As shown in the (Table 3), except for the level of happy memories related to the happiness variable, the mean of other factors (main variables) was not significantly different between the males and females.

\section{The subjects' age}

In the present study, the men's mean age was 20.86 years with a standard deviation of 1.98 years and the women's mean age was 20.57 years with a standard deviation of 1.61 years. According to the result of the 
Table 1. Demographic Data

\begin{tabular}{|c|c|c|c|}
\hline Variable & Male & Female & Total \\
\hline Sex & $152(52)$ & $140(47)$ & 292 \\
\hline Age (yr) & $20.86 \pm 1.98$ & $20.36 \pm 1.61$ & $20.73 \pm 1.81$ \\
\hline Married students & $8(5.4)$ & $8(5.7)$ & $16(5.5)$ \\
\hline In relationship students & $9(6.0)$ & $5(3.6)$ & $14(4.8)$ \\
\hline International branch students & $40(26.8)$ & $34(24.5)$ & $74(25.7)$ \\
\hline Employed students & $18(12.0)$ & $6(4.4)$ & $24(8.4)$ \\
\hline Income (in dollars) & $273.6 \pm 232$ & $143.8 \pm 95.6$ & $235.8 \pm 208$ \\
\hline No. of top students (rank 1-10) & $22(14.8)$ & $25(18.2)$ & $47(16.4)$ \\
\hline Students which study in special schools ${ }^{\text {al }}$ & $125(83.3)$ & $115(84.6)$ & $240(83.9)$ \\
\hline Perceived stress score & $4.83 \pm 2.31$ & $5.05 \pm 2.34$ & $4.9 \pm 2.32$ \\
\hline
\end{tabular}

Data are presented as number $(\%)$ or mean \pm standard deviation.

${ }^{a}$ Schools which require entrance exams.

Table 2. Descriptive Statistics of the Main Factors

\begin{tabular}{lcrr}
\hline \multicolumn{1}{c}{ Factors } & Mean \pm standard deviation & Min & 158 \\
\hline Emotional intelligence & $114.75 \pm 17.13$ & 27 & 43 \\
Self-awareness & $30.83 \pm 4.65$ & 9 & 33 \\
Self-control & $23.63 \pm 4.30$ & 8 & 35 \\
Self-arousal & $23.59 \pm 4.25$ & 6 & 30 \\
Sympathy & $20.15 \pm 3.73$ & 2 & 25 \\
Social skills & $16.61 \pm 3.53$ & 7 & 81 \\
Happiness & $40.34 \pm 11.55$ & 1 & 21 \\
Self-concept & $9.75 \pm 3.70$ & 1 & 9 \\
Life satisfaction & $4.28 \pm 1.87$ & 1 & 12 \\
Emotional readiness & $5.42 \pm 2.41$ & 1 & 6 \\
Spiritual intelligence & $2.85 \pm 1.11$ & 1 & 28 \\
Aesthetic feeling & $7.86 \pm 2.67$ & 1 & 29 \\
Self-efficacy & $7.04 \pm 2.22$ & 1 & 6 \\
Hope-fullness & $3.14 \pm 1.13$ & 17 & 33 \\
Age lyr) & $20.73 \pm 1.81$ & & \\
\hline
\end{tabular}

Table 3. Comparison the Mean of the Variables between Males and Females

\begin{tabular}{|c|c|c|c|}
\hline Factors & Sex & Mean \pm standard deviation & $p$-value ${ }^{a l}$ \\
\hline \multirow[t]{2}{*}{ Emotional intelligence } & Male & $113.66 \pm 17.04$ & 0.259 \\
\hline & Female & $115.93 \pm 17.21$ & \\
\hline \multirow[t]{2}{*}{ Self-awareness } & Male & $30.74 \pm 4.78$ & 0.734 \\
\hline & Female & $30.92 \pm 4.50$ & \\
\hline \multirow[t]{2}{*}{ Self-control } & Male & $23.22 \pm 4.10$ & 0.092 \\
\hline & Female & $24.07 \pm 4.47$ & \\
\hline \multirow[t]{2}{*}{ Self-arousal } & Male & $23.37 \pm 4.22$ & 0.363 \\
\hline & Female & $23.83 \pm 4.27$ & \\
\hline \multirow[t]{2}{*}{ Sympathy } & Male & $20.02 \pm 3.66$ & 0.522 \\
\hline & Female & $20.30 \pm 3.80$ & \\
\hline \multirow[t]{2}{*}{ Social skills } & Male & $16.37 \pm 3.44$ & 0.217 \\
\hline & Female & $16.87 \pm 3.60$ & \\
\hline \multirow[t]{2}{*}{ Happiness } & Male & $40.92 \pm 11.32$ & 0.379 \\
\hline & Female & $39.72 \pm 11.81$ & \\
\hline
\end{tabular}


Table 3. (Continued)

\begin{tabular}{llcc}
\hline \multicolumn{1}{c}{ Factors } & Sex & Mean \pm standard deviation & p-value ${ }^{\text {al }}$ \\
\hline Self-concept & Male & $9.86 \pm 3.57$ & 0.595 \\
Life satisfaction & Female & $9.63 \pm 3.85$ & 0.332 \\
& Male & $4.38 \pm 1.92$ & 0.454 \\
Emotional readiness & Female & $4.17 \pm 1.82$ & \\
Spiritual intelligence & Male & $5.52 \pm 2.43$ & 0.047 \\
Aesthetic feeling & Female & $5.31 \pm 2.40$ & \\
Self-efficacy & Male & $2.72 \pm 1.07$ & 0.251 \\
& Female & $2.98 \pm 1.15$ & \\
Hope-fullness & Male & $8.03 \pm 2.92$ & 0.102 \\
& Female & $7.67 \pm 2.36$ & \\
& Male & $7.25 \pm 2.52$ & 0.952 \\
\hline
\end{tabular}

${ }^{\mathrm{a}}$ By $\mathrm{t}$-test between two independent samples.

student's t-distribution test of the two samples, this difference was not significant (significance=0.209).

The Pearson correlation coefficients test was also done between the participants' age and variables of emotional intelligence and happiness. The only variable that was rational with age among all domains was the 'finding beauty in things' related to happiness. This negative significant difference was observed although it was not strong (significance $=0.046, r=-0.15$ ). In fact, the older the participants get, the lower they find beauty in things.

\section{The personality of the subjects}

One hundred and eighty-two of the participants (64.1\%) were introverted, and 102 (35.9\%) were extroverted. According to the result of independent sample T-test, mean age, emotional intelligence, happiness, and their domains in participants were compared. The results of the test showed that the mean age of the participants in the extroverted and introverted personality groups was not statistically different (significance $=0.898$ )

In both emotional intelligence and happiness variables, the mean of the two domains related to emotional intelligence (including motivation and social skill) and all domains of happiness (including life is rewarding, mentally alert, pleased with self, find beauty in things, satisfied with life, look attractive, happy memories) was significantly different in both extroverted and introverted groups. That is, the average grade of the domains listed above was significantly higher for the extroverted group than the introverted one. Therefore, presumably, the extroverted personality can be a factor in raising happiness. One hundred and ninety-nine students (68.2\%) were studying in basic sciences course and 93 students (31.8\%) were studying in physiopathology course.

\section{Health (percent) and stress levels (percent)}

In this study, the mean and standard deviation of students' health level was $81.60 \pm 15.56$ and the minimum and maximum levels were $7 \%$ and $100 \%$, respectively. Independent-sample $\mathrm{T}$-test result showed that there was no significant difference between the mean of men's and women's health level $(\mathrm{p}=0.666)$.

Furthermore, the mean and standard deviation of the students' stress level was $4.94 \pm 2.33$ and the minimum and maximum levels were $0 \%$ and $10 \%$, respectively. Independent-sample $\mathrm{T}$-test result showed that there was no significant difference between the mean of men's and women's health levels $(\mathrm{p}=0.422)$. Then, the relationship 
between the stress and health levels and variables like age, happiness, emotional intelligence, and related scales was assessed; the Pearson correlation test showed that there was no significant correlation between the subjects' age and health and their stress level. The significance value was 0.817 and 0.274 , respectively.

Data showed that the students' stress level had a negative correlation with both happiness and emotional intelligence and this correlation was statistically significant $(p<0.001, r=0.293)$ and $(p<0.001, r=0.249)$. Also, students' health level had a negative correlation with both happiness and emotional intelligence and this correlation was statistically significant $(\mathrm{p}<0.001, \mathrm{r}=$ $0.376)$ and $(\mathrm{p}<0.001, \mathrm{r}=0.266)$.

Then, the Pearson correlation test was performed to assess the correlation between emotional intelligence and happiness which showed that this correlation was positive and significant $(p<0.001, r=0.464)$. In fact, the two main variables of this study were correlated and this correlation was positive and significant. Thus, an increase in emotional intelligence will probably cause an increase in happiness.

As it is seen the modeling (Table 4), the effect of the independent sex and age variables on the dependent happiness variable was not significant. Also, health and stress levels had a strong and significant correlation with each other. Thus, only one of these two variables should enter the final model to avoid collinearity problem. As a result, these variables were removed from the model and the model was fitted with other independent variables.

Emotional intelligence, level of stress, and grade and type of personality can explain the changes in the happiness level and they were significant effective factors in the last regression pattern (Table 5). As it is seen, the effect of emotional intelligence on happiness score was 0.265 . It means that as other independent variables it is constant; by 1 score increase in emotional intelligence score, there was 0.265 score increase in

\begin{tabular}{|c|c|c|c|c|c|}
\hline \multirow{2}{*}{ Model } & \multicolumn{2}{|c|}{ Unstandardized coefficients } & \multirow{2}{*}{$\begin{array}{c}\text { Standardized } \\
\text { coefficients (beta) }\end{array}$} & \multirow{2}{*}{$\mathrm{t}$-value } & \multirow{2}{*}{ Significance } \\
\hline & B & Standard error & & & \\
\hline Constant value & 12.033 & 9.498 & & 1.267 & 0.206 \\
\hline Sex & -2.073 & 1.226 & -0.091 & -1.691 & 0.092 \\
\hline Age & -0.254 & 0.375 & -0.040 & -0.679 & 0.498 \\
\hline Emotional intelligence & 0.230 & 0.036 & 0.353 & 6.342 & 0.000 \\
\hline Stress level & -0.820 & 0.287 & -0.165 & -2.853 & 0.005 \\
\hline Health level & 0.132 & 0.042 & 0.186 & 3.187 & 0.002 \\
\hline Educational grade & -3.613 & 1.404 & -0.150 & -2.574 & 0.011 \\
\hline Personality model & 5.651 & 1.276 & 0.239 & 4.430 & 0.000 \\
\hline
\end{tabular}

Table 5. Final Modelling of (Linear Regression) Happiness When Age and Sex Are Eliminated from the Model due to No Statistically Meaning and Health Level due to Collinearity

\begin{tabular}{|c|c|c|c|c|c|}
\hline \multirow{2}{*}{ Model } & \multicolumn{2}{|c|}{ Unstandardized coefficients } & \multirow{2}{*}{$\begin{array}{c}\text { Standardized } \\
\text { coefficients (beta) }\end{array}$} & \multirow{2}{*}{ t-value } & \multirow{2}{*}{ Significance } \\
\hline & $\mathrm{B}$ & Standard error & & & \\
\hline Constant value & 13.916 & 4.471 & & 3.112 & 0.002 \\
\hline Emotional intelligence & 0.265 & 0.035 & 0.395 & 7.598 & 0.000 \\
\hline Stress level & -1.061 & 0.258 & -0.211 & -4.118 & 0.000 \\
\hline Educational grade & -3.705 & 1.231 & -0.150 & -3.010 & 0.003 \\
\hline Personality & 6.301 & 1.218 & 0.260 & 5.173 & 0.000 \\
\hline
\end{tabular}

Dependent variable: total happiness. 
happiness. Also, as other independent variables it is constant; by $1 \%$ increase in the student's stress level, happiness score decreased 1.06. The mean of happiness score was 3.7 lower in students of physiopathology period than those of basic science period as other variables are constant. The mean of happiness score of a participant with outward personality was about 6.3 more than the people with introverted personality. It means being introverted is a risk factor for not being happy. It is shown that when all the other variables are constant or zero, the mean score of happiness is about 14 .

\section{Discussion}

In this study, the relationship between emotional intelligence and happiness in medical students was evaluated. There was a statistically significant positive correlation between happiness and emotional intelligence. This indicates that emotional intelligence predicts happiness, and this finding is consistent with the studies by Hasan Nia et al. [15], Tuzhandehjani et al. [16], and Seyed Reza and Soleimani [17]. Emotional intelligence in happiness is a key element and important. Emotional intelligence theorists believe that emotional intelligence leads to increased happiness and high emotional intelligence is a protective mental factor [18].

There was a significant negative relationship between the participants' age and happiness (aesthetic feeling). As the participant's age increases, the aesthetic sense of happiness decreases. There are different views on the relationship between these two variables. According to Morgan et al. [19], happiness has a downward trend to age in developing countries which is consistent with the results of this study. On the other hand, happiness is proportional to age in developed countries, which is not consistent with the results of our research [19].
Also, the strongest predictor of level of happiness in this study population was personality types (introverted and extroverted). The mean of happiness was higher in extroverted people. However, other researches had variable results in this regard; for example, Snel [20] showed that outward personality was a factor for happiness and they were related. It seems that the reason for this association is that outward people have more social activity [21]. Lu and Shih [22] found that there was not any relationship between extroversion and happiness. As people who are less happy are more prone to illnesses [23]. A family physicians can find out people who are introverted and pay more attention to them and prevent their illnesses, so we can reduce health costs.

There was a positive significant relationship between emotional intelligence and perceived health level and students who had higher emotional intelligence feel healthier. Several other studies have shown that there is a significant and positive relationship between emotional intelligence and both general and mental health [24-28]. Several studies on students have shown that information and skills training for students can increase emotional intelligence and, thus, lead to better educational outcomes $[29,30]$.

It is noteworthy that this study is a cross-sectional study and more prospective studies are suggested for exploring the risk factors and confirming the relationship. However, in this study, happiness, emotional intelligence, health status, stress level, and type of personality of students were simultaneously evaluated along with demographic factors, to understand which factor can explain the changes in the happiness level in regression model.

In conclusion, in the studied population, emotional intelligence has a significant positive relationship with happiness. Furthermore, students with higher emotional intelligence felt healthier. Because of the importance of 
mental and physical health in medical students, so the predictive role of emotional intelligence should be considered by authorities.

In this study students who had extroverted personality were significantly happier than students with introverted personality. It is suggested that the students who had introverted personality be more supported to increase their level of happiness. For better understanding of factors in which effect on happiness of medical students, replication of this study in other countries and with prospective design is highly suggested.

\section{ORCID:}

Sulmaz Ghahramani: https://orcid.org/0000-0002-4161-5146; AliReza Torabi Jahromi: https://orcid.org/0000-0001-9325-1957; Danial Khoshsoroor: https://orcid.org/0000-0002-7483-1136; Reza Seifooripour: https://orcid.org/0000-0001-8621-2597; Minoo Sepehrpoor: https://orcid.org/0000-0003-0656-9487 Acknowledgements: The authors would like to thank all the participants in this study and also Deputy of Research of Shiraz University of Medical Sciences for financial support of this study (research code: 1396-01-62-14552). We also thank the research center and consultation and Dr. Nasrin Shokrpour for editing the manuscript. We would like to thank AmirAli Rastegar Kazerooni for his kind contribution in this study.

Funding: The study was financially supported by Deputy of Research of Shiraz University of Medical Sciences.

Conflicts of interest: No potential conflict of interest relevant to this article was reported.

Author contributions: Conception or design of the work: SG, ATJ; acquisition, analysis, or interpretation of data for the work: SG, ATJ, DK, RS, MS; drafting the article: SG, ATJ, DK, RS, MS; and critical revision of the article and final approval of the version to be published: SG, ATJ, DK, RS, MS.

\section{References}

1. Compton WC. An introduction to positive psychology. Belmont, USA: Thomson/Wadsworth; 2005.

2. Lyubomirsky S, King L, Diener E. The benefits of frequent positive affect: does happiness lead to success? Psychol Bull. 2005;131(6):803-855.

3. Pishva N, Ghalehban M, Moradi A, Hoseini L. Personality and happiness. Procedia Soc Behav Sci. 201 1; 30:429-432.

4. Diener E, Oishi S, Lucas RE. Subjective well-being: the science of happiness and life satisfaction. In: Lopez SJ, Snyder CR, eds. The Oxford Handbook of Positive Psychology. 2nd ed. Oxford, USA: Oxford University Press; 2009:187-194.

5. Salovey P, Mayer JD. Emotional intelligence. Imagin Cogn Pers. 1990;9(3):185-211.

6. Schutte NS, Malouff JM, Thorsteinsson EB, Bhullar N, Rooke SE. A meta-analytic investigation of the relationship between emotional intelligence and health. Per Individ Dif. 2007;42(6):921-933.

7. Singh Y, Sharma R. Relationship between general intelligence, emotional intelligence, stress levels and stress reactivity. Ann Neurosci. 2012;19(3):107-111.

8. Carrothers RM, Gregory SW Jr, Gallagher TJ. Measuring emotional intelligence of medical school applicants. Acad Med. 2000;75(5):456-463.

9. Stratton TD, Saunders JA, Elam CL. Changes in medical students' emotional intelligence: an exploratory study. Teach Learn Med. 2008;20(3):279-284.

10. Schutte NS, Malouff JM, Thorsteinsson EB, Bhullar N, Rooke SE. A meta-analytic investigation of the relationship between emotional intelligence and health. Pers Individ Dif. 2007;42(6):921-933.

11. Post SG. Altuism, happiness, and health: it's good to be good. Int J Behav Med. 2005;12(2):66-77.

12. Raosoft. Sample size calculator. http://www.raosoft.com/ 
samplesize.html. Accessed October 20, 2018.

13. Najafi M, Dehshiri G, Dabiri S, Sheikhi M, Jafari N. Psychometric properties of Farsi version of the Oxford Happiness Questionnaire among college students. Train Meas. 2013;3(10):55-73.

14. Mansouri R. Emotional Intelligence Questionnaire Sybrya Schering standardization among students at Tehran University [master's thesis]. Tehran, Iran: University of Allameh Tabatabai; 2000.

15. Hassan Nia S, Saleh Sedghpour B, Ibrahim Damavandi M. Modeling the structural relationship of emotional intelligence and happiness with intermediate of self-efficacy and academic self-regulatory. J Teach Learn. 2014;6(2): 32-60.

16. Tuzhandehjani H, Aughebati A, Tafazzoli A, Kimiayi M, Mahboubeh R, Nasrin C. The effectiveness of teaching components of emotional intelligence on happiness of depressed students. Paper presented at: 6th International Congress on Child and Adolescent Psychiatry; September 17-19, 2013; Tabriz, Tabriz University of Medical Sciences.

17. Seyed Reza S, Soleimani A. The relationship between emotional intelligence and happiness among female and female students. Paper presented at: 8th International Conference on Psychology and Social Sciences; 1396; Tehran, The Society of Seminars of Mehr Ishraq. https://www.civilica. com/Papers-RAFCON06=\%D8\%B4\%D8\%B4\%D9\%85 \%DB\%8C\%D9\%86-\%DA\%A9\%D9\%86\%D9\%81\%D8\% B1\%D8\%A7\%D9\%86\%D8\%B3-\%D8\%A8\%DB\%8C\%D 9\%86-\%D8\%A7\%D9\%84\%D9\%85\%D9\%84\%D9\%84\% DB\%8C-\%D8\%B1\%D9\%88\%D8\%A7\%D9\%86\%D8\%B 4\%D9\%86\%D8\%A7\%D8\%B3\%DB\%8C-\%D9\%88-\%D8 \%B9\%D9\%84\%D9\%88\%D9\%85-\%D8\%A7\%D8\%AC\% D8\%AA\%D9\%85\%D8\%A7\%D8\%B9\%DB\%8C.html. Accessed October 20, 2018.

18. Salovey P, Bedell BT, Detweiler JB, Mayer JD. Coping intelligently: emotional intelligence and the coping process. In: Snyder CR, ed. Coping: The Psychology of What Works.
New York, USA: Oxford University Press; 1999:141-164.

19. Morgan J, Robinson O, Thompson T. Happiness and age in European adults: the moderating role of gross domestic product per capita. Psychol Aging. 2015;30(3):544-551.

20. Snel J. Personality and happiness. Paper presented at: International Conference on the Personality in the Context of Cognition, Emotionality and Motivation II; November 2009; Bratislava, Slovakia.

21. Argyle M, Lu L. The happiness of extraverts. Pers Individ Dif. 1990;11(10):1011-1017.

22. Lu L, Shih JB. Personality and happiness: is mental health a mediator? Pers Individ Dif. 1997;22(2):249-256.

23. Veenhoven R. Healthy happiness: effects of happiness on physical health and the consequences for preventive health care. J Happiness Stud. 2008;9(3):449-469.

24. Namazi A, Alizadeh S, Kouchakzadeh-Talami S. The correlation between general health, emotional intelligence and academic achievement together on midwifery students. J Clin Nurs Midwifery. 2015;4(2):20-28.

25. Neshat MM, Maddineshat M, Sharifi SH, et al. The relationship between emotional intelligence and general health in students of Bojnurd University of Medical Sciences; 2013. J North Khorasan Univ Med Sci. 2014;5(5):10031010.

26. Mehri A, Maleki B, Sedghi Kuhsare S. The relationship between mental health and emotional intelligence among athlete and non-athlete male students in Payam-Noor University, Ardabil Branch. J Health. 2012;2(4):64-74.

27. Tehrani TH, Kabir NK, Cheraghi F, Bekayian M, Yaghoubi Y. The relationship between emotional intelligence and mental health and academic achievement in nursing students of Neishabour University. Sci J Hamadan Nurs Midwifery Fac. 2012;20(3):35-45.

28. Qomi F. A study on the relationship between emotional intelligence and students' health in the Army University of Medical Sciences in the year (doctoral dissertation' Army Medical University). Ann Mil Health Sci Res. 2009;8(1): 
$49-55$.

29. Schutte NS, Malouff JM, Thorsteinsson EB. Increasing emotional intelligence through training: current status and future directions. Int J Emot Educ. 2013;5(1):56.
30. Nelis D, Quoidbach J, Mikolajczak M, Hansenne M. Increasing emotional intelligence: (how) is it possible? Pers Individ Dif. 2009;47(1):36-41. 